\section{俩 Heighten Science \\ P U B L I C I T I O N S Corporation ISSN 2639-6653}

\title{
The impact of skin disorders on patients' quality of life in Malaysia
}

\author{
Yaman Walid Kassab*, Siti Aisha Muhamad², Hiba Khaled \\ Aldahoul' ${ }^{2}$ Imtiaz Khalid Mohammed ${ }^{3}$, Ganesh Sritheran \\ Paneerselvam ${ }^{4}$ and Mohammed Salah Ayad ${ }^{2}$ \\ ${ }^{1}$ Assistant Professor, Department of Hospital and Clinical Pharmacy, Faculty of Pharmacy, \\ Cyberjaya University College of Medical Sciences, Cyberjaya, Selangor, Malaysia \\ ${ }^{2}$ Department of Hospital and Clinical Pharmacy, Faculty of Pharmacy, Cyberjaya University College \\ of Medical Sciences, Cyberjaya, Selangor, Malaysia \\ ${ }^{3}$ Assistant Professor, Department of Pharmaceutical Sciences, Faculty of Pharmacy, Cyberjaya \\ University College of Medical Sciences, Cyberjaya, Selangor, Malaysia \\ ${ }^{4}$ Lecturer, Department of Hospital and Clinical Pharmacy, Faculty of Pharmacy, Cyberjaya University \\ College of Medical Sciences, Cyberjaya, Selangor, Malaysia
}

\begin{abstract}
*Address for Correspondence: Dr. Yaman Walid Kassab, Department of Hospital and Clinical Pharmacy, Faculty of Pharmacy, Cyberjaya University College of Medical Sciences, Persiaran Bestari, 63000 Cyberjaya, Selangor, Malaysia, Tel: +60-174995591; Email:
\end{abstract}

dryamankassab@gmail.com

Submitted: 24 December 2018

Approved: 23 January 2019

Published: 24 January 2019

Copyright: (c) 2019 Kassab YW, et al. This is an open access article distributed under the Creative Commons Attribution License, which permits unrestricted use, distribution, and reproduction in any medium, provided the original work is properly cited

Keywords: Quality of Life (QOL); Acne; Psoriasis; Atopic dermatitis; Malaysia

\section{Check for updates}

\section{Abstract}

Background: Skin diseases is a common worldwide problem. It affected every aspect of patients' quality of life (QOL) mainly physically, socially and psychologically.

Objectives: to assess the impact of skin disorders on patients' quality of life and to identify factors associated with it

Methodology: This cross-sectional study was conducted in outpatient dermatology clinic of a tertiary hospital in Malaysia. A random sample of 145 patients with acne, psoriasis and atopic dermatitis $(A D)$ were interviewed using DLQI questionnaire during their scheduled follow-up appointments at dermatology clinic.

Main outcome measure: Self-reported patients' QOL due to their skin diseases.

Results and discussion: Out of three skin diseases psoriasis patients had the highest prevalence (39.3\%) followed by AD (34.5\%) and acne (26.2\%). Patients' QOL was highly influenced by their skin conditions especially on working/schooling domain. Furthermore, several factors were identified, namely age, working environment, concurrent skin diseases, usage of supplement for skin diseases and type of food as aggravating factors-that may influence patients' QOL. QOL among females and younger adults was found to be more significantly influenced as compared to males and elderly. With respect to working environment, those who had both indoor and outdoor working environment showed the highest impact of their skin conditions on their QOL. Single patients were more influenced by their skin conditions when compared to those who are married, however it was not significant.

Conclusion: Our findings revealed skin disease had negatively impacted individual QOL with different level of aspects. Among the three diseases, AD patients had the worst impact on QOL. Significant predictors of QOL did not relate solely to skin diseases but also other factors such as type of food and working environment.

\section{Introduction}

Skin diseases are a major problem worldwide that affects teenagers and adults. Historically, skin diseases were believed to have insignificant impact on patients' quality of life [1]. More recently, there has been widespread acknowledgment that skin diseases can affect physical, social and psychological aspects of patients' everyday 
lives, as well as their partners, family, and friends [1]. Physical effects depend on the extent of the rash, how active the rash is, its area and associated symptoms, such as itching and flaking. For example, itching has been associated with subjective distress and emotional problems in psoriasis [2]. The social impact of skin conditions is evident in situations that involve closeness and exposure of the skin. Approximately $26 \%$ of patients with psoriasis have experienced that others do not want to touch them [3]. Acne studies reviled that young patients with worse symptoms have difficulties with close relationships and are teased more frequently [4,7]. Studies have also shown that patients with skin conditions namely, acne, atopic dermatitis (AD) and psoriasis are willing to spend and pay much more for a cure for their disease as compared to patients with angina, asthma and hypertension $[7,10]$. A study reported a prevalence range of $25 \%$ to $43 \%$ of skin condition patients affected with psychiatric disorders such as anxiety [8]. Moreover, Ghajarzadeh et al. found that depression as cause of quality of life distress in skin disease patients. This was indicated by social withdrawal, damaged personal relationships and embarrassment [9].

\section{Objectives}

The main objectives of the current study were to: (1) evaluate QOL among patients with dermatological diseases namely, acne, psoriasis and atopic dermatitis, and (2) to investigate the relationship between patients' QoL and various demographic, social, and medical variables.

\section{Method}

This cross-sectional study was conducted from July 2017 to October 2017 at dermatology clinics of a tertiary hospital in Malaysia. A random sample of skin diseases patients, acne, psoriasis or $\mathrm{AD},(\mathrm{n}=145)$ who were attending their scheduled followup appointment at dermatology clinic were included in this study. All patients were interviewed regarding their skin condition and given the translated DLQI questionnaire to complete while waiting the medical consultation in the physicians' waiting room. Data regarding their skin characteristics such as severity of skin disease were recorded by attended physician. All subjects were fully informed and gave their informed consent before participating in the study. Eligibility criteria included patients above 18 years old who had the ability to understand and communicate in Malay language. All aspects of the study protocol were approved by the Medical Research and Ethics Committee (MREC) of the ministry of health, Malaysia (Ref: KKM/NIHSEC/P17-1080) and from the hospital's Clinical Research Center (CRC).

\section{Instrument and tools}

In this study, dermatology life quality index (DLQI) was used to assess the impact of skin diseases on patients' QOL. DLQI was the first dermatology-specific Quality of Life instrument. And considered one of the most frequently used instruments in dermatology studies. It is a simple 10-question validated questionnaire that has been used in over 40 different skin conditions in over 80 countries and is available in over 90 languages. Questions are classified into six domains: symptoms and feelings, daily activities, leisure, working and schooling, personal relationships, and treatment. The score is calculated by summing up the score of each question, resulting in a maximum score of 30 and a minimum score of 0 . The greater the score, the more QOL is impaired [8]. In order to use DLQI in this study, a prior written permission was obtained from the corresponding licensor.

A purpose designed data collection form was also used to extract(a) socio-demographic characteristics (age, gender, ethnicity, marital status, working environment, duration of disease, concurrent skin diseases, family history of skin conditions, usage of supplements, type of food as aggravating factor and comorbidities) was filled by patients and (b) data regarding skin conditions (diagnosis, severity, lesion characteristics and location of skin lesions) was completed by their dermatologist. 


\section{Statistical analysis}

Descriptive statistics were used to describe demographic and clinical characteristics of patients and their QOL scores. Percentages and frequencies were used for the categorical variables, while means and standard deviations were calculated for the continuous variables. To evaluate the relationship between patients' sociodemographic characteristics and their QOL, an independent sample t-test and analysis of variance (ANOVA) test were used for normally distributed data while MannWhitney and Kruskal-Wallis test was used for non-parametric data. All analyses were performed using SPSS statistical software version 23 (SPSS Inc., Chicago, IL, USA). The significance level was set at $\mathrm{p}$ value $<0.05$.

\section{Results}

A total of 145 patients with mean age of 36.7 years $( \pm 15.3)$ were enrolled in this study. Most of the patients were female (65.5\%), Malays (77.2\%), married (60.7\%), and had received bachelor level of education (36.6\%). Majority of the patients were working in an indoor environment (44.1\%) and earning more than the national average income (35.9\%).

Eighty nine percent of the patients had only one skin condition and about $40 \%$ of them had their disease for more than 10 years. Most of patients (28.3\%) did not have any family history of skin disease.

Comorbidities were present in $36.6 \%$ of the patients. Hypertension was the most common disorder (26.3\%), followed by DM, rheumatoid arthritis.

Usage of supplements and food as factor that aggravate skin disease was measured. Among total respondents, $59.3 \%$ uses supplement for their skin conditions and as for food, majority of patients $(60 \%)$ reported that their skin lesions can worsen with some type of food (Table 1).

Among all three skin diseases included in this study, the highest prevalence was for psoriasis (39.3\%) followed by $\mathrm{AD}(34.5 \%)$ and acne (26.2\%). Majority of patients was assessed by their dermatologists as having mild disease (49.6\%). The remaining of patients had moderate (40.0\%) and severe conditions (10.3\%). more QOL is impaired.

The mean DLQI scores obtained was $10.5( \pm 7.5)$ with a range of 0 to 30 . Atopic dermatitis was found to influence patients' QoL the most (DLQI score $=12.92 \pm 7.87$ ) as compared to acne $(9.29 \pm 6.16)$ and psoriasis $(9.26 \pm 7.70)$.

The relationship between the severity of skin condition and its impact on patients' QoL was also tested. Patients with more severe skin conditions reported poorer quality of life (DLQI score in mild cases $=8.64$, DLQI score in moderate cases $=10.91$, DLQI score in severe cases $=18.13$ ) $($ Table 2$)$.

Table 3 shows the impact of skin diseases on each domain of patients' life. The overall patients with skin diseases was $10.5( \pm 7.5)$. Working/schooling domain was the most affected (mean score 56\%), followed by the symptom domain (means score 45.7\%). The personal relationship domain was the least affected (mean score 8.3\%).

Age, working environment, number of skin diseases, usage of dermatological supplements and severity of skin diseases were found to be significant factors that influenced patients' quality of life (Table 4).

QOL among females and younger adults was found to be more significantly influenced as compared to males and elderly. With respect to working environment, those who had both indoor and outdoor working environment showed the highest impact of their skin conditions on their QOL. Single patients were more influenced by their skin conditions when compared to those who are married, however it was not significant. 
Table 1: Patients' socio-demographic data.

\begin{tabular}{|c|c|}
\hline Characteristics & Frequency (\%) \\
\hline \multicolumn{2}{|l|}{ Gender } \\
\hline Male & $50(34.5)$ \\
\hline Female & $95(65.5)$ \\
\hline \multicolumn{2}{|l|}{ Age group } \\
\hline 18-24 years & $33(22.8)$ \\
\hline $25-44$ years & $73(50.3)$ \\
\hline $45-64$ years & $31(21.4)$ \\
\hline$>65$ years & $8(5.5)$ \\
\hline \multicolumn{2}{|l|}{ Ethnicity } \\
\hline Malay & $112(77.2)$ \\
\hline Indian & $15(10.3)$ \\
\hline Chinese & $18(12.4)$ \\
\hline \multicolumn{2}{|l|}{ Marital status } \\
\hline Single/divorced/widow & $57(39.3)$ \\
\hline Married & $88(60.7)$ \\
\hline \multicolumn{2}{|l|}{ Income } \\
\hline No income & $49(33.8)$ \\
\hline$<$ National average income & $27(18.6)$ \\
\hline Within national average income & $17(11.7)$ \\
\hline$>$ National average income & $52(35.9)$ \\
\hline \multicolumn{2}{|l|}{ Working environment } \\
\hline Not working & $59(40.7)$ \\
\hline Outdoor job & $15(10.3)$ \\
\hline Indoor job & $64(44.1)$ \\
\hline Both outdoor and indoor job & $7(4.8)$ \\
\hline Duration & \\
\hline Less than 1 year & $24(16.6)$ \\
\hline $1-2$ years & $31(21.4)$ \\
\hline $2-3$ years & $15(10.3)$ \\
\hline 3-4-years & $9(6.2)$ \\
\hline $4-5$ years & $9(6.2)$ \\
\hline $5-10$ years & $26(17.9)$ \\
\hline More than 15 years & $31(21.4)$ \\
\hline Concurrent skin diseases & \\
\hline One only & $129(89.0)$ \\
\hline Two & $16(11.0)$ \\
\hline Family History & \\
\hline Yes & $41(28.3)$ \\
\hline No & $104(71.7)$ \\
\hline Comorbidities & \\
\hline None & $92(63.4)$ \\
\hline 1 & $28(19.3)$ \\
\hline 2 & $13(9.0)$ \\
\hline$\geq 3$ & $12(8.3)$ \\
\hline Use of supplement for their skin cond & \\
\hline Yes & $86(59.3)$ \\
\hline No & $59(40.7)$ \\
\hline Food as aggravating factor & \\
\hline Yes & $87(60.0)$ \\
\hline No & $58(40.0)$ \\
\hline
\end{tabular}

Table 2: Impact of severity of skin diseases on patients' QOL.

\begin{tabular}{|c|c|c|c|c|c|c|c|}
\hline Skin diseases & No. & $\%$ & DLQI score (Mean \pm SD) & $\begin{array}{c}\text { DLQI Mild } \\
( \pm \text { SD) }\end{array}$ & $\begin{array}{c}\text { DLQI Moderate } \\
( \pm S D)\end{array}$ & $\begin{array}{c}\text { DLQI Severe } \\
( \pm \text { SD })\end{array}$ & P value \\
\hline Psoriasis & 57 & 39.3 & $9.29( \pm 6.16)$ & $7.53( \pm 6.07)$ & $9.00( \pm 7.38)$ & $24.50( \pm 4.51)$ & $<0.001$ \\
\hline AD & 50 & 34.5 & $9.26( \pm 7.70)$ & $9.86( \pm 6.98)$ & $13.80( \pm 6.81)$ & $19.13( \pm 9.25)$ & 0.011 \\
\hline Acne & 38 & 26.2 & $12.92( \pm 7.87)$ & $9.11( \pm 6.13)$ & $9.88( \pm 6.23)$ & $7.00( \pm 7.81)$ & 0.756 \\
\hline Overall & $\mathbf{1 4 5}$ & $\mathbf{1 0 0}$ & $\mathbf{1 0 . 5}( \pm 7.5)$ & $\mathbf{8 . 6 4}( \pm 6.37)$ & $\mathbf{1 0 . 9 1 ( \pm 7 . 0 7 )}$ & $\mathbf{1 8 . 1 3}( \pm 9.72)$ & $<0.001$ \\
\hline
\end{tabular}


Table 3: The impact of skin diseases on each domain of patients' life (based on DLQI Scores).

\begin{tabular}{|c|c|c|c|}
\hline Domains & Mean score & Median score & \% Mean score \\
\hline Symptoms and feelings & $2.74( \pm 1.35)$ & - & 45.7 \\
\hline Daily activities & $1.87( \pm 1.53)$ & - & 31.7 \\
\hline Leisure & $2.11( \pm 1.75)$ & - & 35.2 \\
\hline Work / school & $1.68( \pm 0.99)$ & - & 56.0 \\
\hline Personal relationship & - & 0.50 & 8.3 \\
\hline Treatment & $0.71( \pm 0.87)$ & - & 23.7 \\
\hline Overall & $\mathbf{1 0 . 5}( \pm 7.5)$ & - & $\mathbf{3 5 . 0}$ \\
\hline
\end{tabular}

Table 4: Scores for socio-demographic data on DLQI.

\begin{tabular}{|c|c|c|}
\hline Characteristics & DLQI scores & $P$ value \\
\hline \multicolumn{3}{|l|}{ Gender } \\
\hline Male & $9.44( \pm 7.89)$ & \multirow{2}{*}{0.207} \\
\hline Female & $11.11( \pm 7.33)$ & \\
\hline \multicolumn{2}{|l|}{ Age group } & \multirow{5}{*}{0.003} \\
\hline $18-24$ years & $11.03( \pm 6.45)$ & \\
\hline $25-44$ years & $11.71( \pm 7.47)$ & \\
\hline $45-64$ years & $9.52( \pm 8.24)$ & \\
\hline$>65$ years & $1.63( \pm 1.77)$ & \\
\hline \multicolumn{3}{|l|}{ Ethnicity } \\
\hline Malay & $10.36( \pm 7.07)$ & \multirow{3}{*}{0.738} \\
\hline Indian & $11.83( \pm 10.30)$ & \\
\hline Chinese & $10.27( \pm 7.67)$ & \\
\hline \multicolumn{3}{|l|}{ Marital status } \\
\hline Single & $11.16( \pm 6.84)$ & \multirow{2}{*}{0.422} \\
\hline Married & $10.13( \pm 7.98)$ & \\
\hline \multicolumn{3}{|l|}{ Income } \\
\hline No income & $9.61( \pm 7.68)$ & \multirow{4}{*}{0.533} \\
\hline$<2,300$ & $10.93( \pm 8.74)$ & \\
\hline $2,300-2,500$ & $12.71( \pm 7.82)$ & \\
\hline$>2,500$ & $10.48( \pm 6.84)$ & \\
\hline \multicolumn{3}{|l|}{ Education level } \\
\hline Primary & $9.00( \pm 9.64)$ & \multirow{6}{*}{0.728} \\
\hline Secondary & $10.03( \pm 7.61)$ & \\
\hline Matriculation / Foundation & $7.67( \pm 4.04)$ & \\
\hline Diploma / STPM & $9.55( \pm 7.01)$ & \\
\hline Degree & $11.77( \pm 7.56)$ & \\
\hline Postgraduate (MSc/PhD) & $10.67( \pm 8.09)$ & \\
\hline \multicolumn{3}{|l|}{ Working environment } \\
\hline Not working & $8.95( \pm 7.52)$ & \multirow{4}{*}{0.031} \\
\hline Outdoor job & $11.67( \pm 8.47)$ & \\
\hline Indoor job & $10.98( \pm 6.54)$ & \\
\hline Both outdoor and indoor job & $17.29( \pm 10.86)$ & \\
\hline \multicolumn{3}{|l|}{ Duration } \\
\hline Less than 1 year & $10.83( \pm 6.68)$ & \multirow{7}{*}{0.082} \\
\hline $1-2$ years & $7.68( \pm 6.89)$ & \\
\hline $2-3$ years & $11.8( \pm 7.10)$ & \\
\hline 3-4-years & $8.56( \pm 5.90)$ & \\
\hline $4-5$ years & $15.44( \pm 7.99)$ & \\
\hline $5-10$ years & $12.42( \pm 7.88)$ & \\
\hline More than 10 years & $10.10( \pm 8.30)$ & \\
\hline \multicolumn{3}{|l|}{ Concurrent skin diseases } \\
\hline One only & $11.00( \pm 7.58)$ & \multirow{2}{*}{0.030} \\
\hline Two & $6.69( \pm 6.14)$ & \\
\hline \multicolumn{2}{|l|}{ Family History } & \\
\hline Yes & $10.07( \pm 7.36)$ & 0.648 \\
\hline No & $10.71( \pm 7.64)$ & \\
\hline Comorbidities & & \\
\hline None & $11.04( \pm 7.21)$ & \\
\hline+2 & $11.46( \pm 8.24)$ & 0092 \\
\hline 2 & $9.54( \pm 8.30)$ & 0.092 \\
\hline$\geq 3$ & $5.50( \pm 6.29)$ & \\
\hline Use of supplement & 2 & \\
\hline 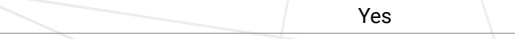 & $8.55( \pm 6.62)$ & 0.000 \\
\hline No & $13.42( \pm 7.92)$ & \\
\hline Food as aggravating factor & & \\
\hline Yes & $12.30( \pm 7.99)$ & 0.000 \\
\hline No & $7.88( \pm 6.00)$ & \\
\hline
\end{tabular}


Unexpectedly, patients with only one skin condition reported more worse QoL as compared to those with two or more skin conditions. With regards to usage of supplement for skin problems, patients who consume supplements had a better QOL as compared to those who refused to use.

Majority of patients reported that some type of food aggravated their skin illness. Skin lesions were reported to be irritated more due to milk and dairy products, nuts, alcohol and seafood which was indicated with a higher mean DLQI score.

\section{Discussion}

This study identified negative impact in QOL of dermatology patients with acne, eczema and psoriasis. Similar findings were described in few international studies $[12,13]$. Skin conditions can adversely affect almost every aspect of a persons' life. Common psychological distress associated with skin diseases include depression, low self-esteem as well as occupational and social problems [5].

Among the three all skin diseases, atopic dermatitis was found to deteriorate patients' QOL the most. A study conducted in Saudi Arabia depicted that AD caused moderate impact with mean DLQI of 8.7 which was significantly below the level in the population of this study [14]. AD can still outgrow in adults where QOL was more impaired in long standing disease.

Other authors have also found that psoriasis possibly leads to the largest impact because of psychological stress that may excruciate symptoms [10]. In addition, compared to other dermatological diseases, acne patients reported a greater levels of anxiety and depression [15]. Meanwhile, data from Hanisah et al. (2009) recorded feeling of frustration, embarrassment and aggressive experienced by $71 \%$ of the subjects due to pimples and acne [16].

This study demonstrated that patients' quality of life can be affected by their skin disease, especially in aspects such as physical symptoms and feelings, social/leisure and work. Biggest impact was seen on work and study aspect followed by symptoms and feelings regardless of the type of skin disease. The result was not surprising as patients with severe skin disease can become too physically disabled to attend for classes or work. Even so, their performance would be compromised if they were able to attend to work/school due to stinging, pain and soreness of skin. A study in Saudi Arabia revealed their skin disease population had emotional domain affected the most followed by symptom domain and functional domain was the least affected [6].

Generally, the impact of skin diseases on patients' QOL varies significantly according patients' age, where the QOL of younger adults aged 18 to 44 was affected more significantly than elderly. Elderly with skin diseases noted a better QOL probably because they tend to accept their skin problems and faced limitations better than non-elderly. Younger patients would have greater concern on the appearance of skin lesions to other people as they were more socially active.

Regarding gender, a higher impact was recorded on women's QOL as compared to men. This could reflect a greater consideration towards aesthetics. However, the mean difference was not significant. This finding was in conformity with findings of previous international studies which reported same DLQI scores for both genders $[10,12]$. Differences among genders were not consistent among studies as disability suffered by female patients were significantly more than males in Saudi Arabia [14]. These variations may be due to differences in populations, sampling methods, settings of study and the spectrum of diseases studied. For psoriasis, this study found more impact of DLQI seen by female and similar result was also found by Augustin et al. [17].

The influence of skin diseases on QOL of patients with different working environment showed a significant difference. Patients with mix indoor and outdoor jobs had the 
highest impact on their quality of life. For instance, an event staff who conducts various functions may exposed to changing of atmosphere where they need to adapt at both surroundings at flexible time as this causes emotional exhaustion and physical weary. Compared to patients who were not working, they would stay probably at home and would less meeting people and socialize. For this they would be more comfortable because their skin was not exposed to environment and human. However, it was not possible to find other articles that addressed this relationship.

Patients with other comorbidities such as hypertension or DM, had a minimal influence of their skin conditions on their quality of life as compared to those without comorbidities. Most of the patients were at younger age where they did not have much comorbidities as elderly would. Young adults with skin diseases were profoundly affected on their self-esteem due to hormonal imbalance and sensitive feelings. QOL also markedly drop in patients with psoriasis owing to its chronic and incurable nature, to a degree that is comparable to that experienced by patients with other chronic diseases, such as cancer, heart disease and DM [12].

Regarding factors associated with QOL, this study reported a higher score in patients who were Indians, single, average income, degree holder and longer duration of disease. Some studies confirmed our findings $[12,17,19]$. However, the comparison was not significant.

With regards to number of concurrent skin diseases, the result was unexpected as patients with only one skin disease had more worse QOL as compared to those with two skin diseases. The reason may be patients with two skin disease had milder pathology or due to small sample size. A study done in Brazil reported similar result [12].

The usage of supplements for skin conditions showed a significant impact on patients' quality of life. Patients who were not using additional therapy for their skin conditions showed to give higher negative consequences on their QOL. The reason behind this was patients may have seen an improvement by the usage of supplements such as tea tree oil, honey and vitamins. As this was supported by many studies that some herbal medications have an anti-inflammatory effect [20].

In our present study, patients agreed that some foods caused worsening of their illness thus impair more on their QOL. Several studies identified the dietary intake (nuts, chocolate, oily and fatty foods, and high sugar content foods) can trigger facial acne and may increase the severity [21]. Some reported that frequency of milk, icecream and dairy intake associated with acne development [22]. There were also studies regarding food on atopic dermatitis. The most commonly reported allergenic foods are eggs, milk, peanuts, wheat, soy, shellfish and fish [23].

In general, relation with skin diseases severity on patients' QOL, it was significantly established between patients with mild, moderate and severe degree. Chronic skin diseases revealed a big difference on DLQI from mild and moderate. This was expected as chronic skin disorders may be exacerbated by emotional stress, personality traits that lead to secondary psychiatric disorder [5]. However, a study reported association of high prevalence of suicidal by certain dermatologic disorders may not always be commensurate with clinical severity of skin disorder [24].

In term of acne problems, the influence of disease on QOL showed higher impairment on mild and moderate acne patients. This study was contradicted with Abdel-Hafez et al., concluded that severe acne patient reported higher scores in DLQI items compared to mild and moderate acne groups [15]. However, several QOL studies using various tools on acne patients reported no significance correlation between acne severity and impairment of QOL $[25,26]$. 
The consequences of psoriasis severity on subjects' QOL showed a significant difference between milder and severe conditions where QOL were largely impacted on more severe psoriasis. This was comparable to a study stated that clinical severity of psoriasis was positively associated with higher DLQI [27]. Patients with moderate or severe psoriasis had significantly associated with hospitalization due to digestive system, mental disorders and their skin disease [18].

Similar with psoriasis, AD patients also had the highest impairment on QOL due to their chronic condition. AD could be physically devastating and socially intruded. They would believe that their disease would have negative consequences on their lives and family. According to Holm et al., there was a significant increase in SCORAD with increasing mean CDLQI/DLQI score (CDLQI/DLQI in mild $=5.30$, moderate $=8.59$, and severe $=11.94 \mathrm{AD}$ ) [28].

\section{Limitation}

One of the main limitations of this study was the small sample size for each the three skin diseases especially acne, which limited the generalizability of conclusions. Another limitation is that this study was conducted in tertiary care center and it is not reflective of patients who receive treatment in primary care setting. For future study could seek to investigate the awareness level of skin disease population regarding skin infection and association with their quality of life.

\section{Conclusion}

This study established that skin disease was negatively affected individual's quality of life. In this population, work and school domain was the most affected where it may contribute to the indirect cost and overall economic burden of skin disease.

Atopic dermatitis was found to be the highest burden in patients' quality of life followed by acne and psoriasis. Clinical severity of skin disease was also influenced patients' quality of life. The assessment of the impact on quality of life in patients with skin diseases is important for clinical management and optimum therapy.

Significant predictors of quality of life did not solely related to skin diseases but also other factors such as type of food and working environment. Present study suggested that physical and psychological support should be given to help patients improve their daily lives besides educate them regarding aggravating factors and awareness of skin infection.

\section{Reference}

1. Hay RJ, Johns NE, Williams HC, Bolliger IW, Dellavalle RP, et al. The Global Burden of Skin Disease in 2010: An Analysis of the Prevalence and Impact of Skin Conditions. J Invest Dermatol. 2010; 134: 1527-1534. Ref.: https://goo.gl/rmHWQM

2. Choi J, Koo JY. Quality of life issues in psoriasis. J Am Acad Dermatol 2003; 49: 57-61. Ref.: https://goo.gl/MsnZsi

3. Pärna E, Aluoja A, Kingo K. Quality of life and emotional state in chronic skin disease. Acta Derm Venereol. 2015; 95: 312-316. Ref.: https://goo.gl/QjGLgq

4. Hong J, Koo B, Koo J. The psychosocial and occupational impact of chronic skin disease. Dermatol Ther. 2008; 21: 54-59. Ref.: https://goo.gl/RnRUzJ

5. Parks L, Balkrishnan R, Hamel-Gariépy L, Feldman SR. The Importance of Skin Disease as Assessed by “Willingness-To-Pay". J Cutan Med Surg. 2003; 7: 369-371. Ref.: https://goo.gl/yPDEis

6. Abolfotouh MA, Al-Khowailed MS, Suliman WE, Al-Turaif DA, Al-Bluwi E, et al. Quality of life in patients with skin diseases in central Saudi Arabia. Int J Gen Med. 2012; 5: 633-642. Ref.: https://goo.gl/zn1rc6

7. Wahl AK, Mørk C, Lillehol BM, Myrdal AM, Helland S, et al. Changes in Quality of Life in Persons with Eczema and Psoriasis After Treatment in Departments of Dermatology. 2006; 86:198-201. Ref.: https://goo.gl/71XYsm 
8. Dunn LK, O'Neill JL, Feldman SR. Acne in Adolescence: Quality of life, self-esteem, mood and psychological disorders. Dermatol Online J. 2011; 17: 1. Ref.: https://goo.gl/dRgtg1

9. Ghajarzadeh M, Ghiasi M, Kheirkhah S. Associations between Skin Diseases and Quality of Life: A Comparison of Psoriasis, Vitiligo, and Alopecia Areata. Acta Med Iran. 2012; 50: 511-515 Ref.: https://goo.gl/PW9wPj

10. Sanclemente G, Burgos C, Nova J, Hernández F, González C, Reyes MI, et al. The impact of skin diseases on quality of life: A multicenter study. Actas Dermosifiliogr [Internet]. 2017; 108: 244-252. Ref.: https://goo.gl/Eb2Gwo

11. Finlay AY, Khan GK. Dermatology Life Quality Index (DLQI)--a simple practical measure for routine clinical use. Clin Exp Dermatol. 1994; 19: 210-216. Ref.: https://goo.gl/fffcPq

12. Tejada Cdos S, Mendoza-Sassi RA, Almeida HL Jr, Figueiredo PN, Tejada VF. Impact on the quality of life of dermatological patients in southern Brazil. 2011; 86: 1113-1121. Ref.: https://goo.gl/zZ2vjy

13. Rani J. A study on awareness of skin infection among adults in Petaling district. Malaysia. 2016; Ref.: https://goo.gl/u5Pg9B

14. Al-Hoqail IA. Impairment of Quality of Life among Adults with Skin Disease in King Fahad Medical City. Saudi Arabia. J Family Community Med. 2009; 16: 105-109. Ref.: https://goo.gl/NcvAQB

15. Abdel-Hafez K, Mahran AM, Hofny ER, Mohammed KA, Darweesh AM, et al. The impact of acne vulgaris on the quality of life and psychologic status in patients from upper Egypt. Int J Dermatol. 2009; 48: 280-285. Ref.: https://goo.gl/nFTSnk

16. Hanisah A, Omar K, Shah SA. Prevalence of acne and its impact on the quality of life in school-aged adolescents in Malaysia. J Prim Health Care. 2009; 1: 20-25. Ref.: https://goo.gl/SSNmn7

17. Augustin M1, Radtke MA. Quality of life in psoriasis patients. Expert Rev Pharmacoecon Outcomes Res. 2014; 14: 559-568. Ref.: https://goo.gl/htoxXd

18. Gulliver WP, MacDonald D, Gladney N, Alaghehbandan R, Rahman P, Baker KA. Long-Term Prognosis and Comorbidities Associated with Psoriasis in the Newfoundland and Labrador Founder Population. J Cutan Med Surg 2011; 15: 37-47. Ref.: https://goo.gl/zJZTbA

19. Yap FB Bin. Cardiff acne disability index in Sarawak, Malaysia. Ann Dermatol. 2012; 24: 158-161. Ref.: https://goo.gl/ywk8H9

20. Williams HC, Dellavalle RP, Garner S. Acne vulgaris. Lancet. 2012; 379(9813): 361-372. Ref.: https://goo.gl/g5W1jF

21. Ghodsi SZ, Orawa H, Zouboulis CC. Prevalence, Severity and Severity Risk Factors of Acne in High School Pupils: A Community-Based Study. J Invest Dermatol. 2009; 129: 2136-2141. Ref.: https://goo.gl/Dhqib4

22. Ismail N, Manaf Z, Azizan N. High glycemic load diet, milk and ice cream consumption are related to acne vulgaris in Malaysian young adults: a case control study. BMC Dermatol. 2012; 12: 13. Ref.: https://goo.gl/JQMDLZ

23. Carlsten C, Dimich-Ward H, Ferguson A, Watson W, Rousseau R, et al. Atopic dermatitis in a highrisk cohort: Natural history, associated allergic outcomes, and risk factors. Ann Allergy, Asthma Immunol. 2013; 110: 24-28. Ref.: https://goo.gl/idfbmx

24. Gupta MA, Gupta AK. Evaluation of cutaneous body image dissatisfaction in the dermatology patient Clin Dermatol. 2013; 31: 72-79. Ref.: https://goo.gl/gt47an

25. Kokandi A. Evaluation of acne quality of life and clinical severity in acne female adults. Dermatol Res Pract. 2010; 2010: 410809. Ref.: https://goo.gl/aLiidA

26. Gupta A, Sharma YK, Dash KN, Chaudhari ND, Jethani S. Quality of life in acne vulgaris: Relationship to clinical severity and demographic data. Indian J Dermatology Venereol Leprol. 2016; 82: 292-297. Ref.: https://goo.gl/z74AZS

27. Schmitt JM, Ford DE. Role of Depression in Quality of Life for Patients with Psoriasis. Dermatology. 2007; 2015;17-27. Ref.: https://goo.gl/WFGByq

28. Holm JG, Agner T, Clausen M, Thomsen SF. Quality of life and disease severity in patients with atopic dermatitis. J Eur Acad Dermatology Venereol. 2016; 30: 1760-1767. Ref.: https://goo.gl/zEFvjX s 